\title{
Efficacy of Eosin B as a New Antimalarial Drug in a Murine Model
}

\author{
Zahra Zamani, ${ }^{1}$ Alireza Sadeghi Tafreshi, ${ }^{2}$ Hossein Nahrevanian, ${ }^{3}$ \\ Behzad Lame-Rad, ${ }^{2}$ Fatemeh Pourfallah, ${ }^{1}$ Hossein Eslamifar, ${ }^{4}$ Sedigheh Sadeghi, ${ }^{1}$ \\ Farideh Vahabi, ${ }^{1}$ Ayda Iravani, ${ }^{1}$ and Mohammad Arjmand ${ }^{1}$
}

\author{
${ }^{1}$ Department of Biochemistry, Pasteur Institute of Iran, Tehran 1316943551, Iran \\ ${ }^{2}$ Department of Biochemistry, Payame Noor University, Tahran 193195, Iran \\ ${ }^{3}$ Department of Parasitology, Pasteur Institute of Iran, Tehran 1316943551, Iran \\ ${ }^{4}$ Department of Clinical Research, Pasteur Institute of Iran, Tehran 1316943551, Iran
}

Correspondence should be addressed to Mohammad Arjmand, arjmand1@yahoo.com

Received 21 May 2012; Revised 28 August 2012; Accepted 27 November 2012

Academic Editor: Donatella Taramelli

Copyright () 2012 Zahra Zamani et al. This is an open access article distributed under the Creative Commons Attribution License, which permits unrestricted use, distribution, and reproduction in any medium, provided the original work is properly cited.

The initial success of any adopted anti-infective strategy to malaria is followed by a descent due to the emergence of resistance to it. The search for new drugs and drug targets is a consistent demand in this disease. Eosin B, a common laboratory dye, is reported to have good antiparasitic properties in vitro. It was studied for its antiparasitic effect in vivo on chloroquine-sensitive Plasmodium berghei murine malaria. Eosin B was administered in 2 different doses by either the oral or parenteral route, once or twice daily to mice infected with Plasmodium berghei. Both the doses of eosin B $400 \mathrm{mg} / \mathrm{kg}$ and $800 \mathrm{mg} / \mathrm{kg}$ gave better results than the controls which were $40 \mathrm{mg} / \mathrm{kg}$ chloroquine and $100 \mathrm{mg} / \mathrm{kg}$ of arteether with $P<0.005$ significance. Percentage suppressive activity by Peter's test of eosin B was better, though at a higher dose than both the controls. Survival rate of mice receiving the higher dose of eosin $\mathrm{B}$ was longer than that of the controls. When administered twice daily, the mice were fully cured after 4 days. Eosin B seems to be a promising drug exhibiting good antimalarial effects in the murine model of the disease.

\section{Introduction}

Malaria is the major cause of morbidity and mortality in tropical countries. In 2010, WHO reported 216 million cases of malaria with an estimated 655,000 deaths, $86 \%$ of the victims were children under 5 years of age, and $91 \%$ of the deaths occurred in Africa. It should; however, be noted that the number of disease cases has decreased for the first time in years and malaria mortality rates have fallen by more than $25 \%$ since 2000 [1]. Different reasons can be evinced for the reemergence of malaria, it could be due to spread of resistance to the first-line antimalarial drugs; cross-resistance between members of the limited number of drug families available; in some areas, multidrug resistance. The search for new drugs is imperative as discovery of new treatments and appearance of resistance to it takes a certain period of time.

In the past decade, Chinese researchers have discovered artemisinin (qinghaosu), the active component of Artemisia annua, a herbal remedy used in Chinese folk medicine for 2000 years. This molecule with its oil-soluble (e.g., artemether and arteether), water-soluble (e.g., artesunate), and semisynthetic derivatives has shown excellent antiPlasmodium efficacy in vitro. They are being used in combination with traditional antimalarials drugs such as mefloquine [2], but there is a ban on artemisinin monotherapy due to recent reports of resistance to artemisinin in Plasmodium falciparum on the Cambodian border [3].

Laboratory dyes have been used as antimalarial drugs for at least a century. Guttmann and Ehrlich described the clinical cure of two patients after oral administration of a thiazine dye, methylene blue in 1891 [4]. It was used for some time, but, disappeared for nearly a century, before surfacing in reports from 1995 onwards and interest has been revived due to its low price. Several clinical trials are in progress, trying to find a suitable drug combination. Methylene blue has been tested both in vitro and in vivo for antimurine malaria activity and on humans in Africa [5]. It has recently been shown that its combination with chloroquine (CQ) is safe in adults and children with and without G6PD deficiency [6]. However, oral MB given twice daily $(4 \mathrm{mg} / \mathrm{kg} /$ day $)$ 
together with a standard dose of CQ over three days was not effective in the treatment of uncomplicated malaria in young children of Nouna town in Burkina Faso in 2003 [7]. In another study, a combination of $\mathrm{MB}$ and amidoqine (MB-AQ), MB and artesunate (MB-AS), and AS-AQ was tested on patients in Burkina Faso. Parasite clearance time differed significantly among the groups and was shortest with MB-AS. By day 14, the rates of adequate clinical and parasitological response after PCR-based correction for recrudescence were $87 \%$ for MB-AS, $100 \%$ for MB-AQ $(P=$ $0.004)$, and $100 \%$ for AS-AQ $(P=0.003)$. The respective figures were the lowest for MB-AS (62\%), intermediate for standard treatment AS-AQ $(82 \%, P=0.015)$, and highest for MB-AQ $(95 \%, P<0.001 ; P=0.03)$ by day 28 [8]. In the same study, strong activity against gametocytes was demonstrated by a combination of MB-AQ and MB-AS together, which showed better activity than AS-AQ during both the incubation period and active malaria [9].

Using molecular docking methods, which predicts the preferred orientation of one molecule to another, eosin B has been identified as a potential antiprotozoan drug [10]. The sensitivity of eosin B was tested in vitro on the apicomplexan parasites, Toxoplasma gondii and a kinetoplastid Leishmania major. A concentration of $180 \mu \mathrm{M}$ reduced Toxoplasma gondii replication inside host cells by $50 \%$, as measured by $\left[{ }^{3} \mathrm{H}\right]$ uracil incorporation, but proved to be a weak inhibitor in Leishmania major. However, further in vitro studies have shown eosin B to be a highly selective, potent inhibitor of a variety of drug-resistant malarial strains, with an average IC (50) of $124 \mathrm{nM}$. Furthermore, there is no indication of cross-resistance with other clinically utilized compounds, suggesting that eosin B is acting via a novel mechanism and it has been suggested that it could be an effective lead compound for development of new, more effective antimalarial drugs [10].

The relative safety of eosin $\mathrm{B}$ has been established previously with Food and Drug Administration (FDA) reports of it not being carcinogenic to mice after a dietary exposure as high as $2.0 \%$ of their weight and approved for use in drugs and cosmetics [11]. We studied its effect on Plasmodium berghei in mice. To our knowledge, this is the first study of its kind wherein its potent inhibitor properties on murine malaria are demonstrated.

\section{Materials and Methods}

Chemicals. Chloroquine (CQ) and arteether (Art) were obtained from J.B. Chemicals and Pharmaceuticals Ltd. (Vatva, Ahmedabad, India) and Themis Medicare Limited (Gujarat, India), respectively. Eosin B, ethanol, and Tween 80 were purchased from Merck (Germany).

Malaria Parasite. P. berghei Haffkine strain was kindly donated by Dr. Nateqpour, School of Public Health, Tehran University, Tehran, Iran. As per the requirement for active parasites, they were maintained by blood passage in NMRI mice when active parasite; otherwise they were stored at $-70^{\circ} \mathrm{C}$ in Alsever's solution $(2.33 \%$ glucose, $0.525 \% \mathrm{NaCl}$, and $1 \%$ sodium citrate in deionised water) and glycerol (9:1 $\mathrm{V} / \mathrm{V})$.

Animals. Animals used in this study were CBA/J (in-bred strain) mice. Maintenance of animals and protocols used were approved by the Ethics Committee of Pasteur institute of Iran. Each group comprised of five mice which were housed in plastic cages under standard laboratory conditions of temperature $\left(22 \pm 1^{\circ} \mathrm{C}\right)$, humidity $(50-60 \%)$ and maintained on a commercially available pellet diet. The course of parasitaemia was monitored by microscopic examination of Giemsa-stained thin blood smears obtained from the tail vein.

Preparation of Drugs. A solution of $70 \%$ Tween 80 and $30 \%$ ethanol was prepared, which was diluted tenfold with sterile distilled water. This solution of $7 \%$ Tween 80 and $3 \%$ ethanol was used as drug vehicle (DV). $160 \mathrm{mg}$ of eosin B was dissolved in $1 \mathrm{~mL}$ of DV to give a stock solution. $100 \mu \mathrm{L}$ of the stock was used undiluted to give a dosage of $800 \mathrm{mg} / \mathrm{kg} / 100 \mu \mathrm{L}$. It was then to give dosages of $400 \mathrm{mg} / \mathrm{kg} / 100 \mu \mathrm{L}, 200 \mathrm{mg} / \mathrm{kg} / 100 \mu \mathrm{L}$, and $100 \mathrm{mg} / \mathrm{kg} / 100 \mu \mathrm{L}$. The four doses were administered intraperitoneally (ip) or given orally (op) to each group of mice. $40 \mathrm{mg}$ of CQ was dissolved in $5 \mathrm{~mL}$ of DV to give a solution of injection containing $8 \mathrm{mg} / \mathrm{mL}$ of CQ; $100 \mu \mathrm{L}$ was injected ip or fed op at a dosage of $40 \mathrm{mg} / \mathrm{kg}$ to another group. In addition, $40 \mathrm{mg}$ of Art was dissolved in $2 \mathrm{~mL}$ of DV to give a $20 \mathrm{mg} / \mathrm{mL}$ solution; $100 \mu \mathrm{L}$ was administered ip and orally into each mouse to give a dosage of $100 \mathrm{mg} / \mathrm{kg}$ in a further group. DV was used as control both orally and ip in the control group. Mice were divided into two groups A and B. Group A was treated by ip and named as A(ip) and op as $A(o p)$ once a day, whereas group $B$ was treated twice a day by the same routes $B(i p)$ and $B(o p)$.

LD50 Test. LD50 test was carried out on CBA/J mice using different dosages of eosin B: 100, 200, 500, 1000, 1400, $1500,2000,2500$, and $3000 \mathrm{mg} / \mathrm{kg}$ ip and the animals were observed for 7 days [12].

Toxicity Assay. Two groups of mice were taken, one group was injected with eosin B (800 mg/kg ip) and the other used as controls. Close attention was paid to any external changes and weight of internal organs. Microscopic preparations of liver; heart; stomach; intestine; kidney; spleen were prepared and examined histopathologically 5, 30, and 60 days after eosin B administration [13].

Mean Survival Time. Mice in both the groups were treated with four different doses of eosin B. Positive control mice were treated with CQ and Art on day 0, $24 \mathrm{~h}$ and $48 \mathrm{~h}$ and the negative control group of mice was tested with DV. These tests were carried out by both the routes (ip) and (op) and the mean survival of each group was noted. 
TABle 1: Percent suppression activity in CBA/J mice with a single dose of drugs as per Peters four-day suppressive test in group A.

\begin{tabular}{|c|c|c|c|c|c|c|}
\hline & $\begin{array}{c}\text { Parasitemia ip } \\
\text { dosage } 96 \mathrm{~h}\end{array}$ & $\begin{array}{l}\text { Suppressive activity } \\
\text { ip } 96 \mathrm{~h}\end{array}$ & $\begin{array}{l}\text { Mean survival time } \\
\text { in days in ip mice }\end{array}$ & $\begin{array}{c}\text { Parasitemia op } \\
\text { dosage } 96 \mathrm{~h}\end{array}$ & $\begin{array}{l}\text { Suppressive activity } \\
\text { op } 96 \mathrm{~h}\end{array}$ & $\begin{array}{l}\text { Mean survival time } \\
\text { in days in op mice }\end{array}$ \\
\hline Eosin $100 \mathrm{mg} / \mathrm{kg}$ & $14.5 \%$ & $27.5 \%$ & 14 & $13 \%$ & $48 \%$ & 15 \\
\hline Eosin $200 \mathrm{mg} / \mathrm{kg}$ & $13 \%$ & $35 \%$ & 15 & $12 \%$ & $52 \%$ & 16 \\
\hline Eosin $400 \mathrm{mg} / \mathrm{kg}$ & $10 \%$ & $50 \%$ & 16 & $7 \%$ & $72 \%$ & 19 \\
\hline Eosin $800 \mathrm{mg} / \mathrm{kg}$ & $7 \%$ & $65 \%$ & 19 & $5 \%$ & $80 \%$ & 21 \\
\hline Art & $8 \%$ & $60 \%$ & 16 & $7.5 \%$ & $70 \%$ & 18 \\
\hline CQ & $10 \%$ & $50 \%$ & 16 & $6.5 \%$ & $74 \%$ & 19 \\
\hline DV & $20 \%$ & & 12 & $25 \%$ & & 12 \\
\hline
\end{tabular}

Results were significant as analyzed by ANOVA $P<0.005$.

Peters' 4-Day Suppressive Test. Peters' 4-day suppressive test was carried out on the above-mentioned mice after determining parasitaemia percentage by microscopic examination of Giemsa-stained blood films taken on day 4 and twice weekly till the 30th day or death of the animal [14]. Differences in parasitaemia percentage between treated groups and untreated animals were analyzed by a one-way ANOVA test using GraphPad Prism 4 and differences considered significant if $P<0.05$. Furthermore, the difference between the mean value of the control group (taken as 100\%) and those of the experimental groups is expressed as percent reduction activity using the following equation:

$$
\text { Activity }=100-\left[\frac{\text { mean parasitemia treated }}{\text { mean parasitemia control }} \times 100\right] .
$$

\section{Results}

Results of Toxicity Assay. No external changes were observed in the two groups of mice. The weight and microscopic specimen of internal organs of infected animals and that of controls showed no difference between the two, indicating no toxicity of eosin B even after two months of administration.

LD50 Test. CBA/J mice died at $3000 \mathrm{mg} / \mathrm{kg}$ eosin B and could tolerate $1500 \mathrm{mg} / \mathrm{kg}$. However, at $2000 \mathrm{mg} / \mathrm{kg}$, half the population of mice died. Different doses from $100 \mathrm{mg} / \mathrm{kg}$ were tested on $\mathrm{CBA} / \mathrm{J}$ mice, but high suppression activity was seen with $800 \mathrm{mg} / \mathrm{kg}$ and $400 \mathrm{mg} / \mathrm{kg}$ dosage of eosin B.

In Vivo Antimalarial Activity of Eosin B as Compared to CQ and Art. Table 1 shows Peters' 4-day suppressive test against P. berghei. The suppression activity exhibited by eosin B was better than CQ and Art, though it was a higher dose as compared to the other two. After $96 \mathrm{~h}$ by the ip route, eosin B at $800 \mathrm{mg} / \mathrm{kg}$ showed the highest antiparasitic activity (65\%) as compared to Art and CQ (60\%) and (50\%), respectively. The op route showed eosin B's activity to be $800 \mathrm{mg} / \mathrm{kg}(80 \%)$ and CQ and Art (70\%) and (74\%).

Mean survival time (MST) of different drugs was recorded by ip route in group A (Figure 1). Eosin B $800 \mathrm{mg}$ showed the highest MST of 19 days, CQ and Art 16 days whereas the controls lived only for 12 days. In group A, by op route (Figure 2) $800 \mathrm{mg}$ eosin B had the longest MST

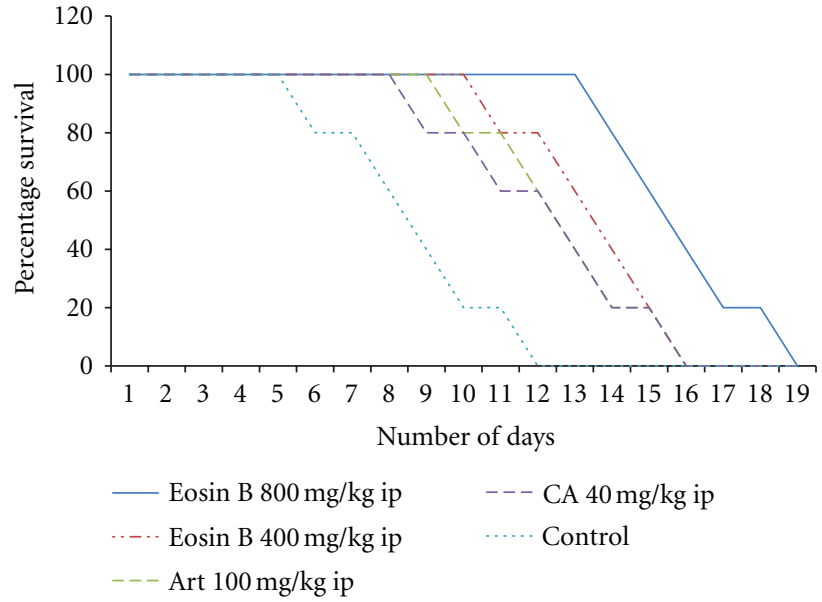

FIGURE 1: Mortality test on CBA/J mice in group A(ip) administered drugs once daily ip for four consecutive days (5 mice per group). Results between test and control were significant by $P<0.005$ as analyzed by ANOVA.

of 21 days and Art, CQ, and eosin B $400 \mathrm{mg} 19$ days and control MST was for 12 days. All the results were significant $(P<0.005)$ as analyzed by ANOVA (Figures 1 and 2$)$.

However, in group B in which eosin B was administered twice daily at 400 and $800 \mathrm{mg} / \mathrm{kg}$ for four days in B(ip) and $\mathrm{B}(\mathrm{op})$ groups and the mice were monitored from the fifth day onwards for 30 days, all the mice were cured except for controls which died on the 13th day. All the results were significant $(P<0.005)$ as analyzed by ANOVA (Figures 3 and 4).

\section{Discussion}

Eosin B is a dibromodinitrofluorescein used for cytoplasmic staining (Figure 4). Molecular docking strategies have predicted it as a good antimalarial drug and in vitro studies have supported the prediction. We carried out an in vivo study on the effect of eosin B on P. berghei, a CQ-sensitive murine malaria strain using it as a new drug. Even though lower doses of chloroquine and artemisine gave protection, but higher doses of the two were used so as to make our studies comparable to the high dose of eosin B utilized. Eosin B has an LD50 of $2000 \mathrm{mg} / \mathrm{kg}$ much higher than the two drugs 


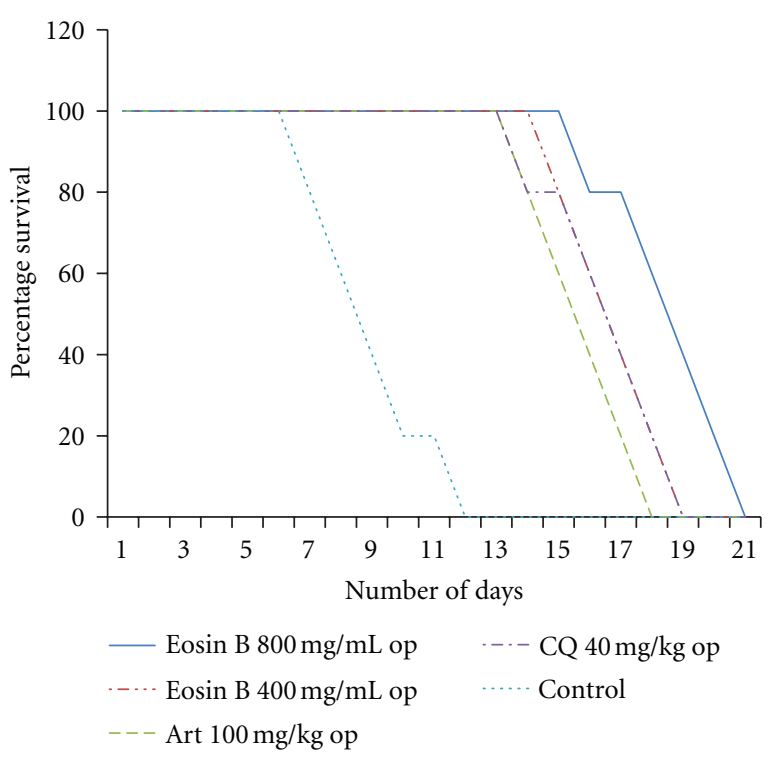

Figure 2: Mortality test on CBA/J mice in group A(op) administered drugs once daily op for four consecutive days ( 5 mice per group). Results between test and control were significant by $P<$ 0.005 as analyzed by ANOVA.

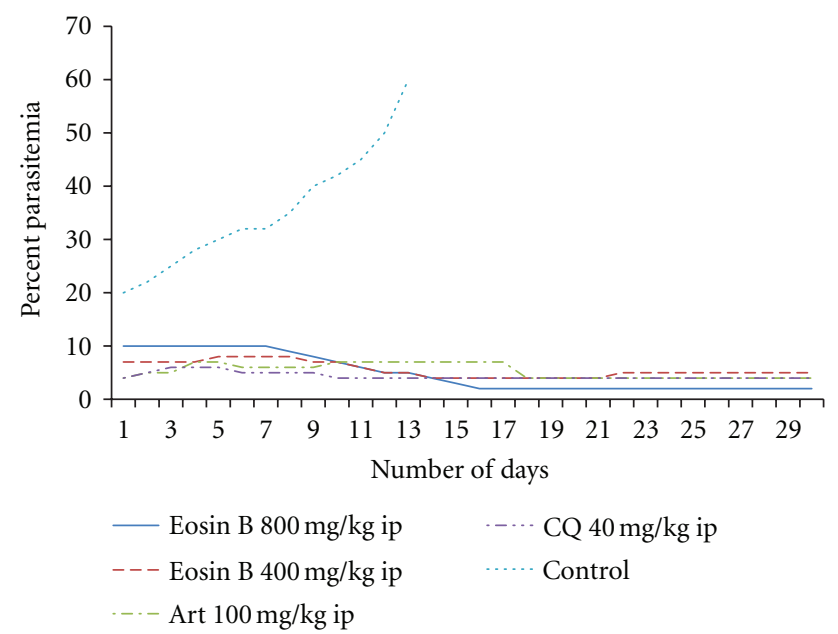

Figure 3: Percent parasitemia in CBA/J mice group B(ip) in ip administered two daily doses of drugs for four consecutive days (5 mice per group). Results between test and control were significant by $P<0.005$ as analyzed by ANOVA.

tested. CQ has an LD50 $330 \mathrm{mg} / \mathrm{kg}$ for op and ip $190 \mathrm{mg} / \mathrm{kg}$. LD50 of Art is reported from $1250 \mathrm{mg} / \mathrm{kg}$ im in Swiss mice as compared to LD50 of artimisinin and artesunate which are $263 \mathrm{mg} / \mathrm{kg}$ im and $475 \mathrm{mg} / \mathrm{kg}$ im, respectively. As LD50 of eosin blue is the highest as compared to the other drugs, hence, higher doses can be tolerated and used in case of resistance development. Eosin B was shown to have a similar if not better effect at the high doses given ip and op (Figures 2 and 3$)$.

Methylene blue, another laboratory dye is a heterocyclic aromatic chemical compound with many uses in various fields, such as biology and chemistry (Figure 4). It has been<smiles>O=C([O-])c1ccccc1-c1c2cc([N+](=O)[O-])c(=O)c(Br)c-2oc2c(Br)c([N+](=O)[O-])c([N+](=O)[O-])cc12</smiles><smiles></smiles>

Methylene blue

Figure 4: Chemical structure of eosin B and methylene blue.

used for malaria in human trials in Burkina Faso [7]. Earlier studies on $P$. yoelii nigeriensis, a murine malaria, showed similar results when given with mefloquine [15]. The mice were cured of $P$. yoelii by 2 daily doses of $2.5 \mathrm{mg} / \mathrm{kg}$ methylene blue or $5 \mathrm{mg} / \mathrm{kg}$ mefloquine by the 6th day, not letting the parasitemia increase more than $6 \%$. LD50 of methylene blue is reported to be $1180 \mathrm{mg} / \mathrm{kg}$ op and $180 \mathrm{mg} / \mathrm{kg}$ ip, much lower than the LD50 reported for eosin B. Side effects of methylene blue have been widely reported including nausea, chest pain, fever, and dizziness but so far for eosin B, besides skin irritation no other side effect has been reported. Also, it has been used in cosmetics with FDA approval, its toxicity dose is $2 \%$ body weight, again much higher than all the other drugs. Dosage trials of methylene blue showed that two daily doses for three days cured the mice infected with $P$. berghei, and a single daily dose had the same antiparasitic effect as Art and CQ. Different dosages of eosin B, from $100 \mathrm{mg} / \mathrm{kg}$ onwards, were studied for antimalarial activity and the effective doses were $400 \mathrm{mg} / \mathrm{kg}$ and $800 \mathrm{mg} / \mathrm{kg}$ much higher than that of methylene blue.

Bioinformatics using docking strategies have shown that eosin B exerts selective antimalarial effects and there is no indication of cross-resistance with other clinically utilized compounds, suggesting that eosin B is acting via a novel mechanism. The antimalarial mode of action appears to be multifaceted and includes extensive damage to membranes, the alteration of intracellular organelles, and enzymatic inhibition not only of DHFR-TS but also of glutathione reductase and thioredoxin reductase. In addition, preliminary studies suggest that eosin B is also acting as a redox cycling compound $[10,16]$.

Eosin B is known as a glutathione-s-transferase inhibitory [17] and preliminary work done by our laboratory has 
also shown its effect on Plasmodium falciparum glutathione$s$-transferase enzyme (data not shown). However, more work will have to be carried out before its mechanism of activity can be determined. Methylene blue has been shown to affect glutathione metabolism of Plasmodium yoelii-infected albino mice.

FDA reports have shown that eosin B is not carcinogenic to mice after a dietary exposure as high as $2 \%$ of body weight [11] and also reported LD50 of eosin B in rats as $3000 \mathrm{mg} / \mathrm{mL}$, similar to our findings. This high LD50, similarity of effective dose by both the routes and tolerance of high doses can be looked upon as an advantage of eosin $\mathrm{B}$, as with emergence of resistance, higher doses can be administered. Our studies, like those of FDA, have shown lack of toxicity even in doses up to $800 \mathrm{mg} / \mathrm{kg}$. Eosin B seems promising as a drug against murine malaria as in vitro studies have shown its effect on Plasmodium falciparum though more research will have to be carried out before this drug can be used for human malaria.

\section{Acknowledgments}

This project has been funded by the Pasteur Institute of Iran during the years 2008-2010. All the authors certify that they have no conflict of interest with each other and have no direct or indirect financial relation with the commercial identity mentioned in the paper.

\section{References}

[1] World malaria Report, 2011, http://www.who.int/malaria/ world_malaria_report_2011/WMR2011_factsheet.pdf.

[2] N. J. White and P. L. Olliaro, "Strategies for the prevention of antimalarial drug resistance: rationale for combination chemotherapy for malaria," Parasitology Today, vol. 12, no. 10, pp. 399-401, 1996.

[3] A. M. Dondorp, F. Nosten, P. Yi et al., "Artemisinin resistance in Plasmodium falciparum malaria," New England Journal of Medicine, vol. 361, no. 5, pp. 455-467, 2009.

[4] P. Guttmann and P. Ehrlich, "Ueber die Wirkung des Methylenblau bei Malaria," Berliner Klinische Wochenschrift, 1891.

[5] J. L. Vennerstrom, M. T. Makler, C. K. Angerhofer, and J. A. Williams, "Antimalarial dyes revisited: xanthenes, azines, oxazines and thiazines," Antimicrobial Agents and Chemotherapy, vol. 39, no. 12, pp. 2671-2677, 1995.

[6] G. Mandi, S. Witte, P. Meissner et al., "Safety of the combination of chloroquine and methylene blue in healthy adult men with G6PD deficiency from rural Burkina Faso," Tropical Medicine and International Health, vol. 10, no. 1, pp. 32-38, 2005.

[7] P. E. Meissner, G. Mandi, S. Witte et al., "Safety of the methylene blue plus chloroquine combination in the treatment of uncomplicated falciparum malaria in young children of Burkina Faso," Malaria Journal, vol. 4, article 45, 2005.

[8] P. E. Meissner, G. Mandi, B. Coulibaly et al., "Methylene blue for malaria in Africa: results from a dose-finding study in combination with chloroquine," Malaria Journal, vol. 5, article 84, 2006.

[9] B. Coulibaly, A. Zoungrana, F. P. Mockenhaupt et al., "Strong gametocytocidal effect of methylene blue-based combination therapy against falciparum malaria: a randomised controlled trial," PLoS ONE, vol. 4, no. 5, article e5318, 2009.

[10] C. E. Atreya, E. F. Johnson, J. J. Irwin et al., "A molecular docking strategy identifies eosin B as a non-active site inhibitor of protozoal bifunctional thymidylate synthase-dihydrofolate reductase," Journal of Biological Chemistry, vol. 278, no. 16, pp. 14092-14100, 2003.

[11] Federal Register, D\&C Red no. 21 and D\&C Red no. 22. Federal Register vol. 47, pp. 53843-53846, 1982.

[12] F. Sperling, "Nonlethal parameters as indices of acute toxicity: inadequacy of the acute LD50," in New Concepts of Safety Evaluation, D. A. Dayan, Ed., p. 177, John Wiley and Sons, New York, NY, USA, 1976.

[13] J. Trevan, "The error of determination of toxicity," Proceedings of the Royal Society B, vol. 101, pp. 483-514, 1927.

[14] W. Peters, "Drug resistance in Plasmodium berghei. Chloroquine resistance," Experimental Parasitology, vol. 17, no. 1, pp. 80-89, 1965.

[15] K. Arora and A. K. Srivastava, "Antimalarial efficacy of methylene blue and menadione and their effect on glutathione metabolism of Plasmodium yoelii-infected albino mice," Parasitology Research, vol. 97, no. 6, pp. 521-526, 2005.

[16] K. M. Massimine, M. T. McIntosh, L. T. Doan et al., "Eosin $\mathrm{B}$ as a novel antimalarial agent for drug-resistant Plasmodium falciparum," Antimicrobial Agents and Chemotherapy, vol. 50, no. 9, pp. 3132-3141, 2006.

[17] H. Zimmerman and K. Fritz Wolf, WIPO Patent Application WO/2006/097472 BECKER-BRANDENBURG, 2006, http:// www.sumobrain.com/patents/wipo/Novel-inhibitors-glutathione-s-transferase/WO2006097472.html. 


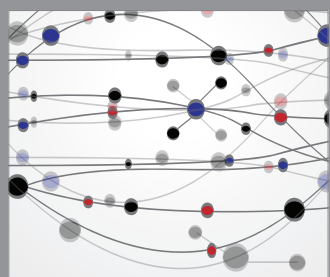

The Scientific World Journal
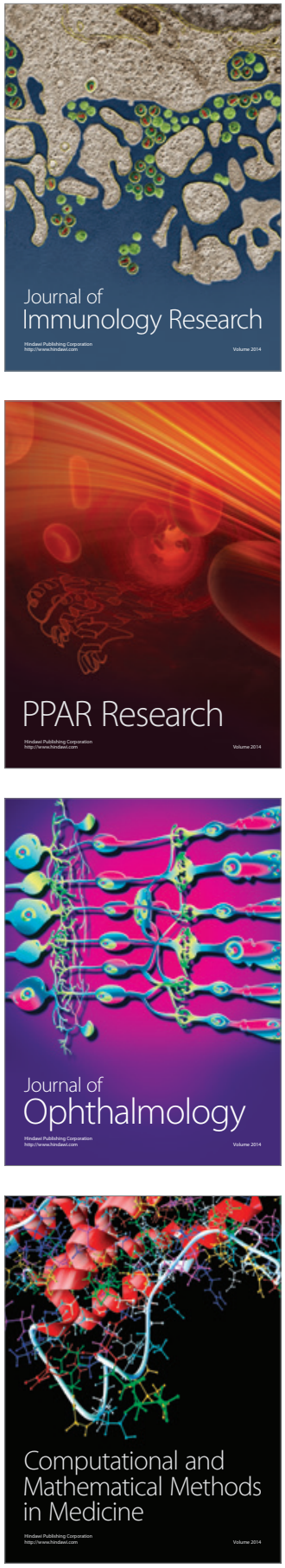

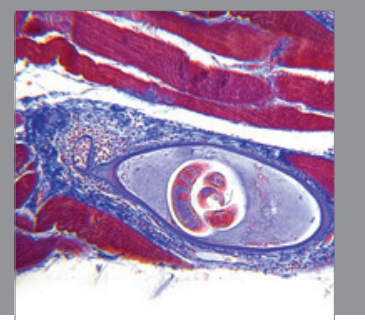

Gastroenterology

Research and Practice
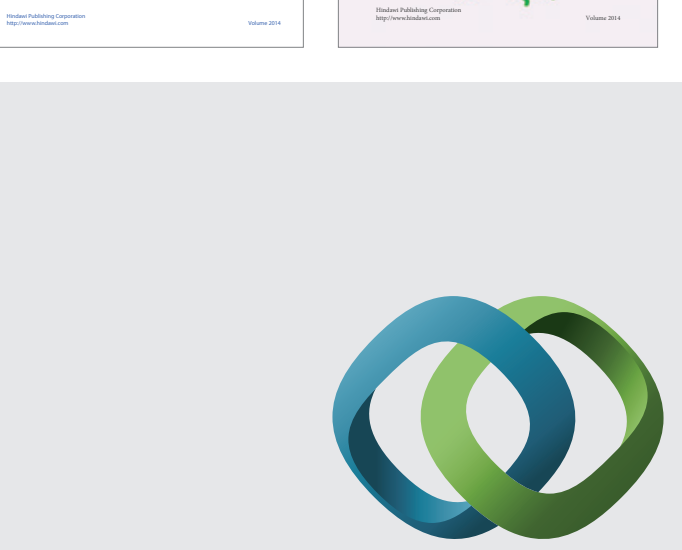

\section{Hindawi}

Submit your manuscripts at

http://www.hindawi.com
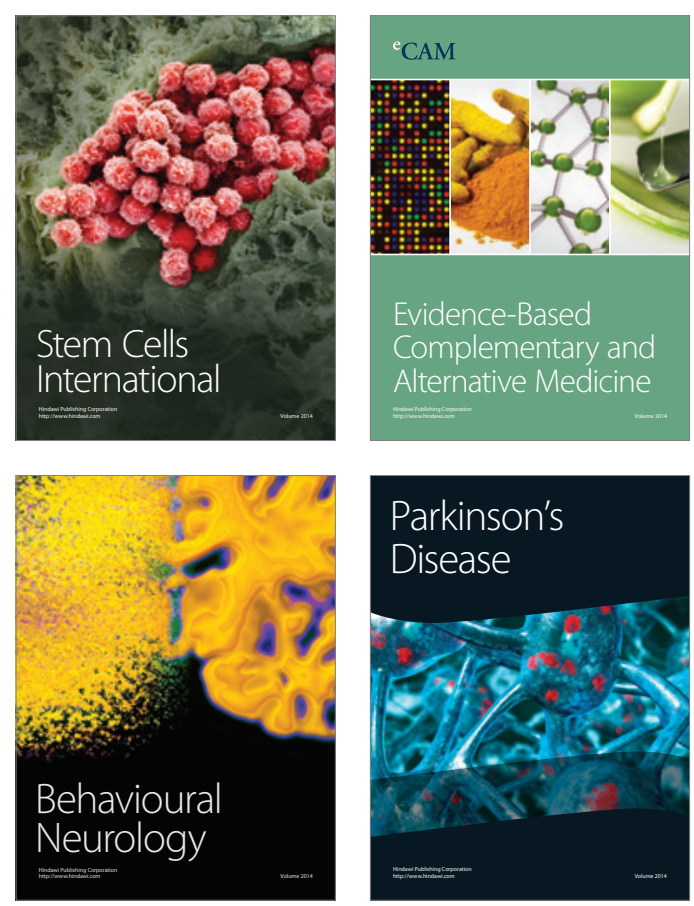

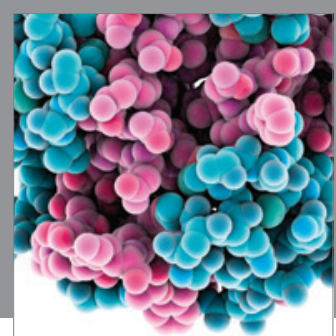

Journal of
Diabetes Research

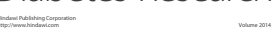

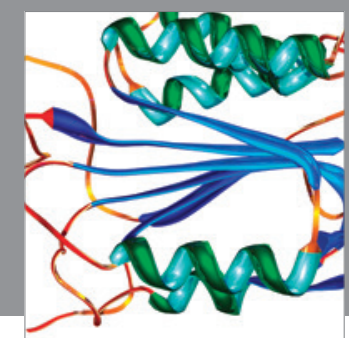

Disease Markers
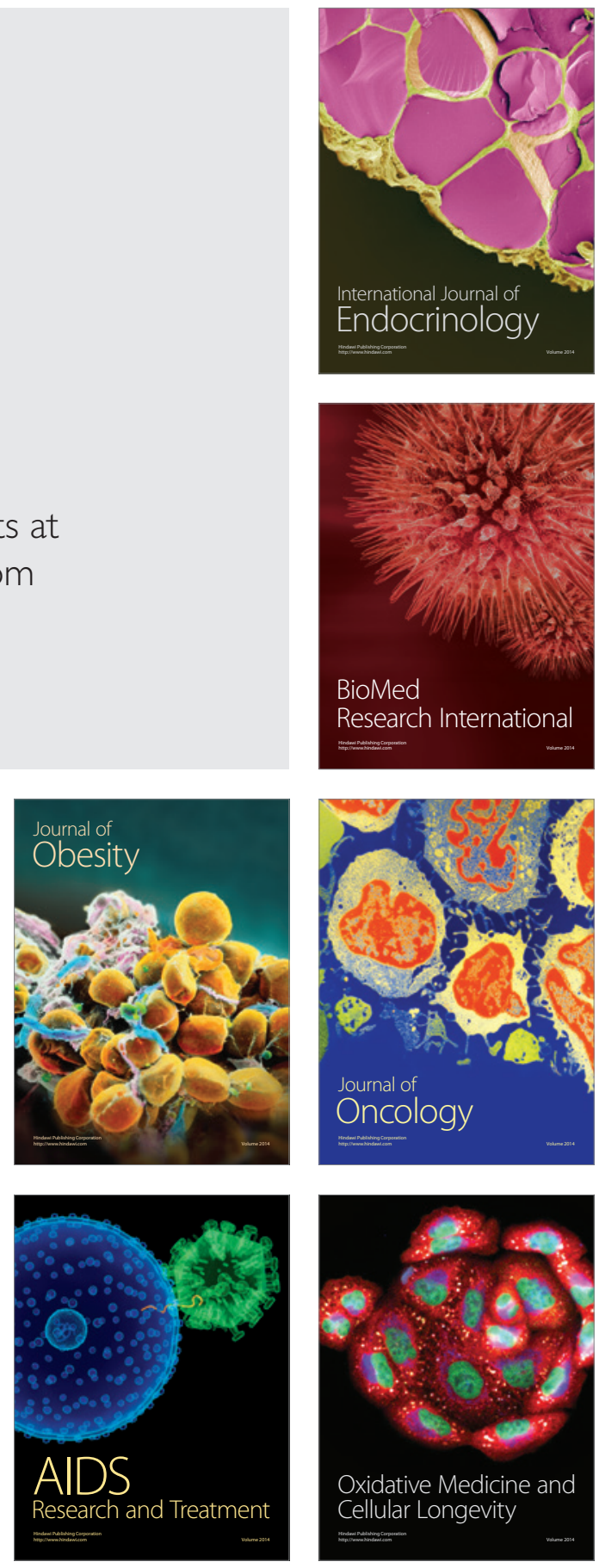